
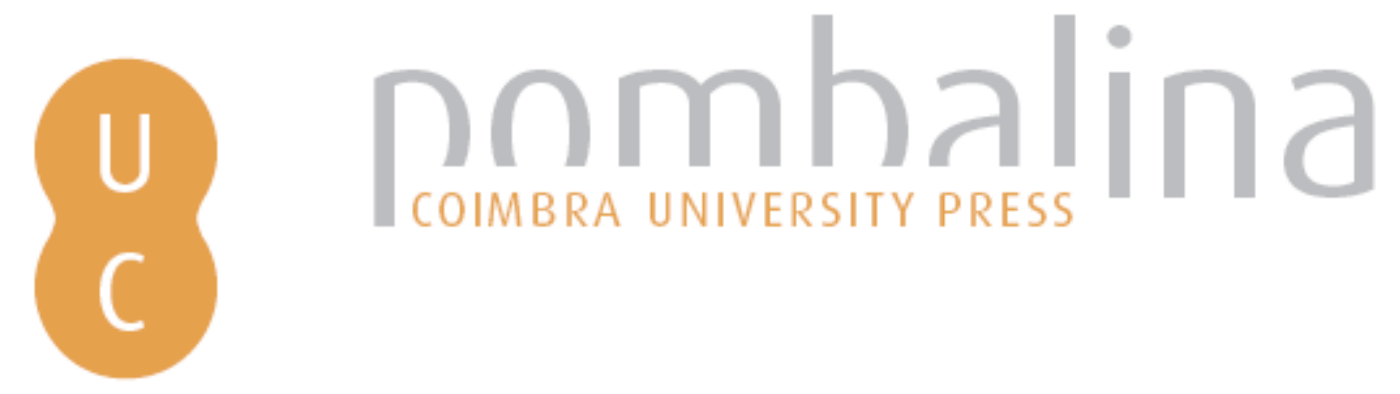

\title{
Do direito da família aos direitos familiares
}

Autor(es): $\quad$ Sousa, Miguel Teixeira de

Publicado por: Imprensa da Universidade de Coimbra

URL

persistente:

URI:http://hdl.handle.net/10316.2/38894

DOI:

DOI:http://dx.doi.org/10.14195/978-989-26-1113-6_16

Accessed : $\quad$ 26-Apr-2023 13:02:09

A navegação consulta e descarregamento dos títulos inseridos nas Bibliotecas Digitais UC Digitalis, UC Pombalina e UC Impactum, pressupõem a aceitação plena e sem reservas dos Termos e Condições de Uso destas Bibliotecas Digitais, disponíveis em https://digitalis.uc.pt/pt-pt/termos.

Conforme exposto nos referidos Termos e Condições de Uso, o descarregamento de títulos de acesso restrito requer uma licença válida de autorização devendo o utilizador aceder ao(s) documento(s) a partir de um endereço de IP da instituição detentora da supramencionada licença.

Ao utilizador é apenas permitido o descarregamento para uso pessoal, pelo que o emprego do(s) título(s) descarregado(s) para outro fim, designadamente comercial, carece de autorização do respetivo autor ou editor da obra.

Na medida em que todas as obras da UC Digitalis se encontram protegidas pelo Código do Direito de Autor e Direitos Conexos e demais legislação aplicável, toda a cópia, parcial ou total, deste documento, nos casos em que é legalmente admitida, deverá conter ou fazer-se acompanhar por este aviso.

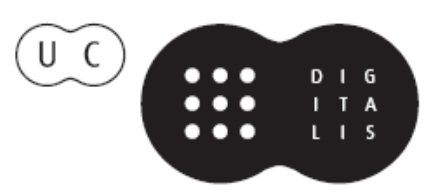




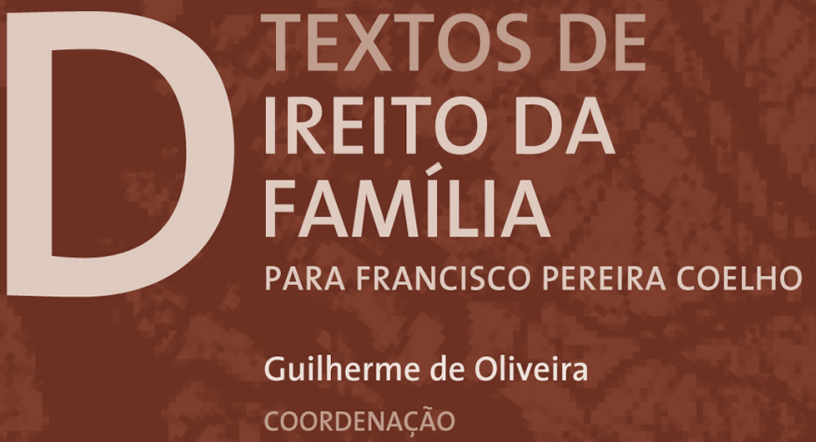




\section{DO DIREITO DA FAMÍLA}

\section{AOS DIREITOS FAMILIARES}

Miguel Teixeira de Sousa Professor Catedrático da Faculdade de Direito de Lisboa, Advogado

\section{Enquadramento geral}

\subsection{Aspeto histórico}

Tal como a família, também o direito da família tem sofrido significativas alterações na sua já longa história1. Muito frequentemente, essas alterações são o reflexo de modificações sociais, culturais e políticas; noutras vezes, é o legislador que, através de ruturas legislativas, pretende fomentar modificações sociais ou culturais.

A evolução do direito da família mostra as seguintes grandes linhas:

- A laicização (ou secularização) do direito da família, no duplo sentido de substituição das fontes canónicas pelas fontes estaduais e da sua aplicação universal, ou seja, independente da orientação religiosa dos seus destinatários; esta evolução atingiu particularmente o casamento, que, independentemente do caráter sacramental que a Igreja Católica lhe atribui (cf.

${ }^{1}$ Cf., por exemplo, Goody, Família e Casamento na Europa, passim; GoOdy, The European Family (1999). 
cân. 1055, § 1. ${ }^{\circ}$, CIC), ficou subordinado ao direito estadual, nomeadamente no que respeita à sua dissolução pelo divórcio;

- A orientação do direito da família mais para a proteção do indivíduo dentro do grupo familiar do que para a proteção da família como grupo ("desinstitucionalização" e "individualização" da família)2: "em vez de ser o indivíduo que "pertence» a uma família, é a família que se coloca ao serviço do indivíduo" ${ }^{3}$ o que pode ser visto como consequência de um deslocamento do "sentimento do "nós" da comunidade familiar [...] para o sentimento do "eu» livre e solitário" «; é significativo que, a par dos múltiplos preceitos que se referem aos interesses dos membros da família (cf., por exemplo, art. $1673 .^{\circ}$, n. $^{\circ} 1,1676 .^{\circ}, \mathrm{n} .^{\circ} 2,1875 .^{\circ}$, n. $^{\circ} 2,1878 .^{\circ}, \mathrm{n} .^{\circ} 1,1978 .^{\circ}$, n. ${ }^{\circ} 2$, e $1988 .^{\circ}, \mathrm{n} .^{\circ} 2^{5}$ ), apenas um preceito - o art. $1671 .^{\circ}$, n. ${ }^{\circ} 2$ - se refira ao bem da família (ainda assim devendo o mesmo ser ponderado em conjunto com os interesses de cada um dos cônjuges) e um outro preceito - o art. $1677 .^{\circ}-\mathrm{C}-$ aos

\footnotetext{
${ }^{2}$ Cf. BECK/BECK-GERnSHeIM, Das ganz normale Chaos der Liebe (1990), 13: "O que é, significa, deveria ser ou poderia ser a família, o casamento, a paternidade, a sexualidade, o erotismo, o amor não pode mais ser pressuposto, interrogado, enunciado de forma vinculativa, antes varia em conteúdos, fronteiras, normas, moral, possibilidade, por fim, eventualmente de indivíduo para indivíduo, de relação para relação, devendo ser desvendado, negociado, acordado, fundamentado em todas as particularidades do como, do quê, do porquê, do porque não, mesmo quando desta maneira os conflitos e os diabos, que devem estar adormecidos e sossegados em todos os detalhes, são despertados e desencadeados"; cf. também BECK-GERNSHEIM, Theoretical Inq. L. 13 (2012), 1 ss.; sobre a matéria, cf. também SCHWAB, FamRZ 1995, 514 e 516 ss.; WAGENITZ/BARTH, FamRZ 1996, 577 s.; EEKELAAR, IJJF 1 (2010), 17 ss. ("[...] in order to be justified, family-related normative expressions should enhance the well-being of individual in the family"); críticos perante esta evolução, cf. ERHARDT SOARES/LEITE DE CAMPOS, ROA 50 (1990), 5 ss.; LEITE DE CAMPOS, ROA 54 (1994), 920 ss.; construindo uma alternativa ao liberalismo, cf. LIFSHITZ, Theoretical Inq. L. 13 (2012), 44 ss.

3 BÉNABENT, Rev. trim. dr. civ. 71 (1973), 495.

${ }^{4}$ Meulders-KLEIN, Droit e Société 23/24 (1993), 170.

5 Pertencem ao Código Civil os artigos citados sem indicação do diploma de origem.
} 
interesses morais da família do ex-cônjuge; esta orientação conduz ao abandono da welfare thesis, ou seja, da orientação segundo a qual as restrições impostas aos membros da família são justificadas pelo bem da família (ou por aquilo que se pode entender corresponder a esse bem $)^{6}$; mesmo o critério do superior interesse da criança (cf. art. $3 .^{\circ}$, n. $^{\circ} 1, \mathrm{CDirCr}$ ) destina-se, além do mais, a proteger a criança de outros membros da família, o que justifica o crescente intervencionismo estadual na área da proteção dos menores;

- O alargamento do espaço de autorregulamentação que é concedido aos membros da família, pelo que se pode dizer que o direito da família assume, de forma intencional, uma "purposive abstention"; esta característica do direito da família é coerente com o "individualismo institucionalizado" que é próprio das sociedades modernas e que, aliado a um processo de autodeterminação, decorre do "desequilíbrio institucionalizado entre o indivíduo desinserido e os problemas globais numa sociedade de risco global";;

- A submissão do direito da família aos princípios da igualdade entre os cônjuges (cf. art. $36 .^{\circ}$, n. $^{\circ} 3$, CRP) - que é uma consequência da emancipação da mulher verificada no decurso do século XX -, da não discriminação entre filhos legítimos

\footnotetext{
${ }^{6}$ Cf. EeKelaAR, Family Law and Personal Life (2006), 9 ss.; EeKelaAR, in KATZ/ EeKelaAR/MAClEAN (Eds.), Cross Currents/Family Law and Policy in the US and in England (2000), 637 ss.

${ }^{7}$ EEKELAAR, Theoretical Inq. L. 13 (2012), 91.

8 BeCK/BeCK-GERnsheim, Das ganz normale Chaos der Liebe, 11 ss.; BECK/ BECK-GERNSHEIM, Individualization/Institutionalized Individualism and Its Social and Political Consequences (2002), xxi e xxii; numa análise mais pormenorizada, BECK, Risikogesellschaft/Auf dem Weg in eine andere Moderne (1986), 206, afirma que a individualização comporta uma tríplice dimensão: uma "dimensão de libertação", relativa à dissociação das formas e vinculações sociais preexistentes, uma "dimensão de desmitificação", respeitante à perda das garantias tradicionais em matéria de conhecimento de ação, de crenças e de normas orientadoras, e uma "dimensão de reintegração", relativa à nova forma de laço social que resulta da individualização.
} 
(nascidos de pais casados) e ilegítimos (nascidos fora do casamento) (cf. art. 36. ${ }^{\circ},{ }^{\circ} 4, \mathrm{CRP}$ ) e da prevalência do interesse do filho menor; esta prevalência é uma decorrência do reconhecimento de direitos à criança e traduz-se tanto no abandono de uma relação hierárquica entre pais e filhos, como na orientação das responsabilidades parentais para a realização dos interesses dos filhos (sobre o conteúdo destas responsabilidades, cf. art. $1878 .^{\circ}, \mathrm{n} .^{\circ} 1$ );

- A dissociação entre a comunhão de vida conjugal e o casamento, isto é, a aceitação tanto de uma comunhão de vida fundada no casamento, como de uma comunhão de vida não matrimonial; a evolução desta dissociação mostra que ela comportou duas fases distintas: numa primeira, verificou-se o mero reconhecimento de uma situação de facto; numa segunda, passou a aceitar-se a constituição de uma comunhão de vida não matrimonial (como é o caso da união de facto (cf. art. $1 .^{\circ}, \mathrm{n} .^{\circ} 2, \mathrm{LUF}$ );

- A progressiva diminuição da importância do status familiar e a crescente relevância do contrato ${ }^{9}$ ou da mera situação de facto, como se comprova pela construção quer de institutos de base contratual com influência no status (como, por exemplo, o divórcio por mútuo consentimento (cf. art. $1773 .^{\circ}$, n. $^{\circ} 1$ )), quer de institutos de base contratual que não implicam nenhum status (como, por exemplo, o apadrinhamento civil (cf. art. $2 .^{\circ}$ LAC)), quer ainda de institutos a que a lei se limita a reconhecer os seus efeitos (como é o caso da união de facto (cf. art. $1 .^{\circ}$, n. $^{\circ} 2$, LUF));

- A neutralização do género, no sentido de que os regimes jurídico-familiares tendem a abstrair do sexo dos membros da família; exemplo típico desta neutralização é a admissibi-

9 Cf. SCHWENZER, Eur. L. Reform 3 (2001), 200. 
lidade de casamentos entre pessoas do mesmo sexo (cf. art. $\left.1577 . .^{\circ}\right)^{10}$;

- A "judicialização" da solução dos conflitos familiares, ou seja, a solução dos conflitos entre os membros da família através da decisão de um juiz, e a aceitação da mediação familiar em matérias que cabem no âmbito da autorregulamentação permitida aos membros da família (o que, num certo sentido, diminui essa "judicialização").

\subsection{Política legislativa}

O regime jurídico da família é o resultado de três opções fundamentais. Uma delas respeita à dicotomia entre o público e o privado: trata-se de saber se a proteção deve ser dada à família qua tale ou aos seus membros. Uma outra opção fundamental refere-se à dicotomia entre a intervenção e a autonomia: o que se procura saber é se a família deve ser regulada apenas pelo direito da família ou se esta mantém um espaço de autonomia para a aplicação de regras não jurídicas (nomeadamente, ético-sociais) ou até para a não aplicação de nenhumas regras. Finalmente, uma outra opção situa-se igualmente no plano da política legislativa, mas relaciona-se com a finalidade do direito da família: trata-se de saber se o direito da família se deve orientar por objetivos ou por direitos.

Para o primeiro termo desta última alternativa, o direito da família deve fomentar certos propósitos (como, por exemplo, o bem- estar da criança) e avalia os seus institutos pela sua capacidade para atingir esses propósitos; para o segundo, o direito da família deve atribuir direitos, sem se preocupar com as consequências ${ }^{11}$.

10 Cf. HERRING, LF 11 (2009), 5 ss.

${ }^{11}$ Cf. PARKER, Mod. L. Rev. 55 (1992), 319 ss., referindo-se a uma dicotomia entre "utility" e "rights"; cf. também DEWAR, Mod. L. Rev. 61 (1998), 470 ss., concluindo, aliás, que este "pluralismo normativo" se insere num mais amplo "normal chaos of family law"; cf. também DEWAR/PARKER, in KATZ/EEKELAAR/MACLEAN (Eds.), 
O significativo é que o atual direito da família balança entre uma orientação utilitarista ou (consequencialista) e uma perspetiva deontologista:

- A orientação utilitarista não se compromete com a atribuição de direitos aos membros da família e serve-se da discricionariedade como critério de escolha ou de composição de interesses; esta orientação é prevalecente na vasta área da proteção da criança;

- A perspetiva deontologista opera com direitos e deveres e utiliza critérios normativos de decisão na defesa desses direitos; esta perspetiva é dominante nas igualmente vastas áreas das relações entre cônjuges e do estabelecimento da filiação.

Relevante é igualmente que, mesmo em áreas nas quais predomina tradicionalmente uma perspetiva utilitarista e um critério de discricionariedade, a posição dos direitos tem vindo a ser reforçada: pense-se, por exemplo, na área do direito dos menores e nos direitos atribuídos à criança ${ }^{12}$. A tendência inversa também se tem verificado, pois que se suprimiram direitos em zonas do direito da família tradicionalmente dominadas pela perspetiva deontologista: basta pensar na supressão das causas subjetivas do divórcio (assentes na violação culposa dos deveres conjugais) e na sua substituição por causas objetivas assentes na rutura da vida em comum (cf. art. 1781. ${ }^{\circ}$, al. d)) e atentar na consequente desvalorização dos deveres conjugais - ainda enumerados no art. $1672 .^{\circ}$ - que é implicada por esta alteração legislativa.

Cross Currents/Family Law and Policy in the United States and England (2000), 123 ss.; EEKELAAR, in MACLEAN (Ed.), Family Law and Family Values (2005), 19 ss., distinguindo, como possíveis fontes de "personal obligations", "rule-based duties" $\mathrm{e}$ "duties associated with virtue".

12 Cf. DewAr, Int'1 J.L. Pol. \& Fam. 14 (2000), 66 ss. 


\section{2. Âmbito da regulação}

\subsection{Generalidades}

A família é uma realidade multifacetada, assentando, entre outros, em fatores biológicos, morais, afetivos e sociais. O direito da família não pode constituir um sistema autónomo perante o seu meio envolvente. No direito da família, a oposição entre o legal e o ilegal não pode deixar de considerar a contraposição entre o biológico e o não biológico, entre o moral e o imoral, entre o afeto e o desafeto ou entre o socialmente aceitável e o socialmente censurável13.

A família é, pela sua natureza, um espaço de autorregulação e de autonomia, o que tem importantes implicações para o papel reservado ao direito da família. Na verdade, o direito da família regula, em grande medida, o que está autorregulado e intervém para limitar a autonomia dos membros da família, o que significa que esse direito só releva nas situações de crise em que, nomeadamente, seja necessário proteger um desses membros ou resolver conflitos entre esses membros. Em suma: o direito da família é, fundamentalmente, o direito das crises familiares.

\subsection{Espaço ajurídico}

Na família há necessariamente um espaço de intimidade e de privacidade que o direito não pode pretender regular: esse espaço tem de ser igualmente um espaço ajurídico ou livre de direito. Basta pensar, por exemplo, no tipo de relacionamento íntimo que os cônjuges adotam, nos valores que os pais querem transmitir aos filhos ou na educação que lhes pretendem dar.

13 Sobre alguns princípios ético-jurídicos do direito da família, cf. DIEDERICHSEN, FS Karl Larenz (1983), 145 ss. 


\section{Características do regime}

\subsection{Caráter pluralista}

O direito da família não deve ser utilizado como um instrumento de imposição de uma certa ideologia social ou moral, mas, pelo contrário, espelhar as conceções sociais e morais dominantes numa determinada sociedade - incluindo, como é próprio das sociedades pluralistas, o valor da tolerância. Na atualidade, uma conceção liberal do direito da família é a única aceitável: um direito da família liberal não tem de ser neutral perante todas as formas possíveis de família ${ }^{14}$ - isso corresponderia, não a uma conceção liberal, mas uma conceção anarquista -, mas não pode impor nenhuma forma de vida familiar, nem restringir as várias alternativas possíveis para alcançar a "vida boa" (no sentido da eudaimonia aristotélica)15. O liberalismo é incompatível com a imposição de qualquer mundividência, pelo que tem de aceitar como admissível - também em termos políticos - qualquer divergência socialmente aceitável sobre as formas de vida dos cidadãos ${ }^{16}$.

O direito da família não deve - nem pode - impor um determinado modelo de relação matrimonial ou paramatrimonial ou de relação entre pais e filhos. O que se espera do direito da família é uma "ssupportive neutrality”", dado que ele "deve ser um apoio nas escolhas individuais respeitantes a acordos familiares e estilos de vida, mas esforçar-se por ser neutral perante pessoas que fazem

${ }^{14}$ Cf., na perspetiva de defesa dos "liberal goods", GALSTON, Liberal Purposes/ Goods, virtues, and diversity in the liberal state (1991), 78 ss.

15 ARISTÓTElEs, Etica a Neucómico (trad. port., 2004), 1095a 15 a 22, onde se refere a eudaimonia ao "viver bem e comportar-se bem" (melhor do que o "viver bem e passar bem" proposto na tradução portuguesa).

16 Cf., com base numa public reason, isto é, numa razão que pode ser reconhecida por diferentes conceções morais ou políticas, RAWLS, Political Liberalism (1993), 213 ss.; cf. também RaWls, U. Chi. L. Rev. 64 (1997), 765 ss. e 787 ss. 
diferentes escolhas"17. Não é possível construir um sistema de direito da família sem atender ao meio social e cultural em que ele se insere e também não é possível fechar o direito da família a esse meio envolvente, pelo que, embora seja inevitável que o direito da família legislado (o family law of the books) seja frequentemente desestabilizado pelas mudanças ocorridas nesse meio ambiente, há que procurar evitar as discrepâncias entre o direito legislado e as práticas sociais realmente vividas (o family law in action). Dito de outro modo: o direito da família deve ser compatível com uma "pluralisation", pois que só esta permite uma "individualisation" dos modos de vida familiar ${ }^{18}$.

\subsection{Caráter individualista}

a) A função realizada pelo direito da família tem vindo a modificar-se substancialmente nos tempos mais recentes. Em substituição de uma tradicional função de regulamentação próxima da realidade institucional familiar, no moderno direito da família é particularmente evidente a "pulverização do direito em direitos subjetivos"19, já que, em nome da proteção de um "hiperindividualismo" 20 , esse direito tem vindo a acentuar a posição de cada um dos membros no âmbito da família e, consequentemente, a preocupar-se em definir os direitos de cada um deles perante os outros membros e, inclusivamente, em proteger cada um dos membros da família dos poderes que qualquer outro membro reivindique em nome da comunidade

17 CHAMBERS, U. Mich. J.L. Reform 18 (1984/1985), 814 s.; cf. também GLENDON, State, Law and Family/Family Law in Transition in the United States and Western Europe (1977), 122.

18 Cf. ROTHENBACHER, in EEKELAAR/NHLAPO (Eds.), The Changing Family/Family Forms \& Family Law (1998), 10.

19 Cf. CARBonnier, Droit et passion du droit sous la vème République (1966), 121.

20 Cf. THÉRY, Le démariage (1993), 378. 
familiar ${ }^{21}$. A família deixou de ser vista como um intermediário (isto é, como um dos conhecidos corps intermédiaires) entre o Estado e $\mathrm{o}$ indivíduo 22 .

b) A este propósito é interessante procurar fazer um breve relance histórico. Durante muitos séculos, a família foi, num certo sentido, um espaço livre de direito, dado que, durante todo esse tempo, o direito deixava que a instituição familiar se regulasse a ela própria. As obrigações familiares eram criadas pela própria família e eram assumidas (ou consideradas como assumidas) pelos seus membros como uma autovinculação destes perante os outros membros.

A situação não se alterou radicalmente com as primeiras codificações oitocentistas, dado que estas, se é certo que deixaram de conceber a família como um espaço livre de direito, receberam, no essencial, o regime institucional da família, nomeadamente na atribuição do papel de chefe de família ao cônjuge marido e à distinção (e discriminação) entre filhos nascidos no casamento e fora do casamento. Se é certo que as obrigações familiares passaram a ser obrigações jurídicas, também é verdade que essas obrigações não eram mais do que a reprodução das obrigações institucionais ${ }^{23}$. Tratou-se, portanto, de uma fase essencialmente caracterizada pela receção do regime institucional da família pelo direito.

${ }^{21}$ Cf. EEKELAAR, Family Law and Personal Life, 195: "It is in protecting individuals against the power individuals hold in communities (including families) where law, or legal-type institutions can have a primary role"; cf. também BECK-GERNSHEIM, in BECK/BECK-GERNSHEIM (Eds.), Riskante Freiheiten (1994), 115, reportando-se à "postfamiliale Familie" e à passagem "Von der Notgemeinschaft zur Wablverwandtschaft"; FRANK, FamRZ 2004, 846 s.

22 Cf. GLENDON, The Transformation of Family Law (1989), 298 ss.; sobre a "Individualisierungsthese" - isto é, sobre a tese da progressiva dissolução das relações pessoais nas sociedades modernas -, cf. HILL/KOPP, Familiensoziologie/ Grundlagen und theoretische Perspektiven 5 (2013), 261 ss.

23 ENNECCERUS/NIPPERDEY, Allgemeiner Teil des bürgerlichen Rechts ${ }^{15}$ (1959), 454 , ainda referiam que os direitos familiares são atribuídos aos respetivos titulares como contrapartida dos "deveres éticos" (sittliche Pflichten) que cabem a outros membros da família. 
O panorama só se começou a alterar no segundo pós-guerra, fundamentalmente na sequência da proibição da discriminação da mulher perante o marido (algo que, pelo menos em alguns aspetos, o direito canónico ambicionava desde a Idade Média). Esta proibição levou a atribuir à mulher os mesmos direitos reconhecidos ao marido e favoreceu a construção de um direito da família baseado em direitos tanto de cada um dos cônjuges, como dos filhos, o que levou, por vezes, a esquecer completamente a dimensão institucional (ou, se se preferir, supraindividual) da família.

O direito português contém atualmente dois excelentes exemplos desta tendência. Um deles é a possibilidade de o direito à compensação de um dos cônjuges pela sua contribuição acima do exigível e com sacrifício profissional para os encargos da vida familiar ser exigido, se os cônjuges estiverem casados no regime da separação, durante a constância do casamento (art. 1676. ${ }^{\circ}$, n. $^{\circ} 2$ e 3). Um outro exemplo é a separação entre o decretamento do divórcio (aliás, baseado apenas em causas objetivas) e a reparação dos danos causados por um dos cônjuges ao outro (art. 1792. ${ }^{\circ}$, n. $^{\circ}$ 2): para não "perturbar" o direito ao divórcio de um dos cônjuges, qualquer pedido de reparação contra ele tem de ser formulado fora da ação de divórcio.

\subsection{Caráter imperativo}

a) O direito da família é um ramo jurídico no qual predominam as normas imperativas e inderrogáveis, o que se compreende facilmente atendendo a que, como os membros da família tendem a regulamentar as suas relações e a deixar-se influenciar nessa regulamentação pela importância da família e pelas tradições sociais a ela ligadas, para o direito legislado restam apenas as matérias que o legislador pretende subtrair à vontade desses membros. No direito da família, a autonomia privada caracteriza-se, não tanto pelo poder de substituir os regimes legais, como pela faculdade de escolher entre diferentes regimes legais (como acontece, por exemplo, quanto ao regime de 
bens: cf. art. $1698 .^{\circ}$ ) ou de regular, de maneira informal, aquilo que não está coberto pelo direito.

b) Esta situação justifica algumas restrições significativas à liberdade negocial no domínio do direito da família ${ }^{24}$. Algumas restrições respeitam à exclusão do papel da vontade nalguns aspetos regulados pelo direito da família. Assim, em concreto:

- Os direitos e os negócios familiares estão submetidos a um numerus clausus e a um princípio de tipicidade (cf., por exemplo, art. $1714 .^{\circ},{ }^{\circ}{ }^{\circ} 1$, quanto à imutabilidade do regime de bens, mesmo se resultante de uma convenção antenupcial);

- O conteúdo dos estados familiares e dos direitos e deveres familiares está fixado legalmente, não podendo ser alterado ex voluntate (cf., por exemplo, art. $1672 .^{\circ}$, quanto aos deveres conjugais; art. $1852 .^{\circ}$, quanto à perfilhação; art. $1878 .^{\circ}$, quanto às responsabilidades parentais; art. $2003 .^{\circ}$, quanto ao direito a alimentos);

- A vontade é irrelevante para produzir determinados efeitos; assim, por exemplo, os pactos sucessórios constantes da convenção antenupcial são irrevogáveis (art. 1701. ${ }^{\circ}$, n. ${ }^{\circ}$ 1); o regime de separação de bens é imperativo em certas circunstâncias (art. $1720 .^{\circ}$ ); a doação entre casados é nula se entre os cônjuges vigorar imperativamente o regime de separação de bens (art. $1762 .^{\circ}$ e $1720 .^{\circ}$ ); as doações entre esposados não são revogáveis por mútuo consentimento (art. 1758. ${ }^{\circ}$ ); a separação judicial de bens é irrevogável (art. 1771. ${ }^{\circ}$ ); a perfilhação é irrevogável (art. 1858. ${ }^{\circ}$ ); as responsabilidades parentais são irrenunciáveis (art. 1882. ${ }^{\circ}$ ); a adoção plena é

${ }^{24}$ Cf. P. AlBuQuerQue, Autonomia da vontade e negócio jurídico em Direito da Família (1986), 20 ss. e 32 ss.; sobre as caraterísticas dos negócios familiares, cf., ainda com interesse, BEITZKE, FS Werner Flume I (1978), 317 ss. 
irrevogável (art. $1989 .^{\circ}$ ); o direito a alimentos é irrenunciável e não pode ser cedido (art. $2008 .^{\circ}$, n. $^{\circ} 1$ );

- Os acordos entre os membros da família (cf., por exemplo, art. $1673 .^{\circ}, \mathrm{n}^{\circ}{ }^{1} 1,1770 .^{\circ}, \mathrm{n} .^{\circ} 2,1773 .^{\circ}, \mathrm{n} .{ }^{\circ} 2,1775 .^{\circ}, \mathrm{n} .^{\circ} 1$, al. a) e b), c) e d), $1779 .^{\circ},{ }^{\circ}{ }^{\circ} 2,1793 .^{\circ}$, n. $^{\circ} 2,1875 .^{\circ}, n{ }^{\circ} 2$, $1901 .^{\circ}$, n. $^{\circ} 2,1903 .^{\circ}, 1905 .^{\circ}, 1906 .^{\circ}$, n. $^{\circ} 5$ e $7,1907 .^{\circ}, n .^{\circ} 1$, $2005 .^{\circ}$, n. $^{\circ} 1$, e $\left.2006 .^{\circ}\right)$ não têm caráter contratual; trata-se antes de uma convergência de vontades que não se fundem numa vontade comum e, portanto, de uma convergência de dois atos jurídicos para uma determinada finalidade.

c) Outras restrições à relevância da autonomia da vontade no âmbito do direito da família referem-se ao regime dos negócios jurídicos familiares. Em concreto:

- A lei define os requisitos dos negócios familiares, nomeadamente os requisitos atinentes aos pressupostos (como o regime dos impedimentos matrimoniais (art. $1600 .^{\circ}$ a $1609 .^{\circ}$ )), os requisitos respeitantes à forma (cf., v. g., art. $1615 .^{\circ}$ e $1616 .^{\circ}$ (forma do casamento)), e ainda os requisitos referidos ao conteúdo (cf., por exemplo, art. 1698. (conteúdo da convenção antenupcial));

- A lei determina os efeitos dos negócios familiares, em especial, os efeitos pessoais; assim, por exemplo, conforme resulta do art. $1618 .^{\circ}$, os cônjuges não podem alterar os deveres conjugais emergentes do casamento (art. 1672. ${ }^{\circ}$ ), nem sequer por convenção antenupcial (art. $1699 .^{\circ}$, n. ${ }^{\circ} 1$, al. b));

- A lei define o regime de extinção e de modificação voluntária dos negócios familiares; por exemplo: não são voluntariamente revogáveis nem as convenções antenupciais (art. 1714..$^{\circ}$ ), nem as doações entre esposados (art. 1758. ${ }^{\circ}$ ), nem o casamento, cuja dissolução, ainda que obtida por mútuo consentimento, exige uma sentença do tribunal ou uma decisão do conservador do registo civil (art. 1773. ${ }^{\circ}$ ). 
d) Por fim, importa considerar as hipóteses em que a lei fornece determinados parâmetros para o exercício da autonomia privada pelos membros da família. É o que sucede, por exemplo, quanto à escolha pelos cônjuges da residência da família: esta escolha deve atender, entre outros aspetos, às exigências da vida profissional dos cônjuges e aos interesses dos filhos e deve procurar salvaguardar a unidade da vida familiar (cf. art. $1673 .^{\circ}$, n. ${ }^{\circ}$ ).

\subsection{Caráter indeterminado}

O direito da família deve construir um sistema que possa ser constantemente adaptado ao meio envolvente. Isso pode ser facilitado pela técnica legal do recurso a conceitos indeterminados 25 . Lembre-se, por exemplo, o conceito de "bem da família" (cf. art. $1671 .^{\circ}$, n. $^{\circ}$ 2), de "encargos da vida familiar" (cf. art. 1675. ${ }^{\circ}, \mathrm{n} .^{\circ} 1$ ), de "contribuição [...] consideravelmente superior" de um dos cônjuges (cf. art. 1676. ${ }^{\circ}$, n. 3 ), de "rutura definitiva do casamento" (cf. art. 1781. ${ }^{\circ}$, al. d)), de "condições análogas às dos cônjuges" (cf. art. 1871..$^{\circ}$, n. ${ }^{\circ} 1$, al. c)), de "interesse dos filhos" (cf. art. $1673 .{ }^{\circ}$, n. ${ }^{\circ} 1$, e $1878 .^{\circ}$, n. $^{\circ} 1$ ), de "superior interesse da criança" (cf. art. 1974. $.^{\circ},{ }^{\circ}$ 1), de "desenvolvimento físico, intelectual e moral dos filhos" (cf. art. $1885 .^{\circ}$, n. $^{\circ}$ 1), de "questões de particular importância para a vida do filho" (art. 1906..$^{\circ}$ n. 1 e 2), de "perigo para a segurança, saúde, formação moral e educação do filho" (cf. art. 1918..$^{\circ}$ e de "tudo o que é indispensável ao sustento, habitação e vestuário" (cf. art. $2003 .^{\circ},{ }^{\circ}{ }^{1}$ ).

Os conceitos indeterminados têm de ser concretizados ${ }^{26}$. O interessante é verificar que, em certas áreas do direito da família, a lei

\footnotetext{
25 Cf. H. RoQue, LF 4 (2005), 93 ss.

${ }^{26}$ Interessante é a afirmação de MNOOKIN/KORNHAUSER, Yale L. J. 88 (1978-1979), 979 s., de que os conceitos indeterminados criam situações de desigualdade entre as partes, porque a sua disponibilidade para assumir o risco e a sua capacidade para chegar a um acordo podem diferir substancialmente.
} 
estabelece um critério para essa concretização: sempre que a questão seja apreciada num processo de jurisdição voluntária (como acontece, por exemplo, quanto a várias questões relativas a menores: cf. art. $1500^{\circ}$ OTM), essa concretização é realizada segundo um critério de conveniência e oportunidade (cf. art. 987. ${ }^{\circ} \mathrm{CPC}$ ), ou seja, de acordo com um critério de discricionariedade.

\subsection{Caráter formal}

A fim de garantir a certeza e a segurança jurídicas, os negócios e demais atos jurídicos familiares são formais. É o que sucede, por exemplo, com o casamento (cf. art. 1615..$^{\circ}$ ), a convenção antenupcial (cf. art. $1710^{\circ}$ ), a reconciliação entre cônjuges separados de pessoas e bens (cf. art. $1795 .^{\circ}-\mathrm{C}$, n. $^{\circ} 2$ e 3 ), a perfilhação (cf. art. $1853 .^{\circ}$ ) e a designação de tutor pelos pais (cf. art. 1928. ${ }^{\circ}$, n. ${ }^{\circ}$ 3).

\section{Relações familiares}

As relações jurídicas familiares correspondem a estruturas e a comportamentos sociais assentes na realidade sociológica da família, pelo que elas não apresentam uma função constitutiva, mas tão só reguladora dessa mesma realidade. As relações familiares estão submetidas a um numerus clausus, pelo que não é possível constituir direitos e celebrar negócios familiares distintos dos previstos na lei.

As relações familiares são por natureza duradouras, pelo que não se extinguem com o decurso do tempo, e definem os chamados estados pessoais (como o de filho, solteiro, casado, divorciado ou viúvo). O estado pessoal corresponde a uma situação relativamente estável que é definida em função das relações familiares decorrentes do parentesco e do casamento (ou não casamento). Diferentemente do que sucede com a generalidade das relações duradouras, as re- 
lações familiares não podem ser denunciadas, o que, naturalmente, também vale para os correspondentes estados pessoais.

\section{Direitos familiares}

\subsection{Estados pessoais}

Os estados pessoais são eficazes erga omnes, isto é, têm de ser respeitados por todos. É nesta base que assenta a indivisibilidade ou unidade dos estados pessoais (que encontra uma exceção, por exemplo, no disposto no art. $1856^{\circ}$ quanto à eficácia da perfilhação de filho pré-defunto).

Da oponibilidade absoluta dos estados pessoais é reflexo a eficácia erga omnes do caso julgado das ações referidas a esses estados (art. 622. ${ }^{\circ} \mathrm{CPC}$ ), embora com algumas exceções tanto nas ações de investigação de maternidade (art. 1819. ${ }^{\circ},{ }^{\circ}{ }^{\circ}$ 2) e de paternidade (art. 1873. ${ }^{\circ}$ ), como nas ações de impugnação da paternidade (art. 1846. ${ }^{\circ}$, n. 2 2. ${ }^{\text {a }}$ parte): em todos estas hipóteses, o caso julgado não é oponível aos herdeiros e legatários que não tenham sido demandados.

A referida eficácia erga omnes restringe-se ao estado pessoal, não abrangendo os fundamentos da decisão. Assim, por exemplo, o que adquire eficácia erga omnes é o estado pessoal decorrente do divórcio, do estabelecimento da maternidade ou da impugnação da paternidade, não os fundamentos pelos quais o divórcio foi decretado, a maternidade foi reconhecida ou a paternidade foi impugnada. É por isso que, por exemplo, após a impugnação da paternidade nada impede que se volte a estabelecer a paternidade no mesmo progenitor: todos estão obrigados a respeitar o resultado da impugnação - o de que $A$ não possui o estado de filho de $B-$, mas não estão todos obrigados a respeitar que $A$ não seja filho de $B$. 


\subsection{Direitos pessoais}

a) Os direitos familiares pessoais podem pertencer a um de dois tipos: esses direitos podem ser originários, quando são atribuídos diretamente ao seu titular (como, por exemplo, o direito ao divórcio ou o direito a estabelecer a filiação), ou derivados, quando são recíprocos de deveres impostos a outrem (como, por exemplo, os direitos recíprocos dos deveres conjugais: cf. art. $1672 .^{\circ}$ ).

Os direitos familiares pessoais decorrem dos estados pessoais e, por isso, comungam das características destes mesmos estados. Assim, aqueles direitos são duradouros, tal como o são os estados familiares a que se prendem e dos quais são expressão. Os direitos familiares perduram enquanto se mantiverem os estados familiares que os originam, pelo que, por exemplo os direitos do cônjuge ou do filho mantêm-se enquanto permanecer o casamento ou se conservar estabelecida a filiação.

Os direitos familiares pessoais, ao contrário do que acontece com os estados pessoais, não são eficazes erga omnes, pois que a correspondente conduta só pode ser exigida a um determinado membro familiar. Os direitos familiares pessoais possuem um caráter relativo e não são oponíveis a terceiros, pelo que a estes não pode ser exigido o cumprimento de nenhum direito familiar pessoal ${ }^{27}$. Por exemplo: os deveres dos cônjuges (cf. art. 1672..$^{\circ}$ ) não são eficazes perante terceiros, pelo que nenhum terceiro está obrigado a respeitá-los e nenhum dos cônjuges tem direito a exigir a sua observância por um terceiro ou exigir deste uma indemnização pela sua violação. Os deveres conjugais são deveres dos cônjuges entre si, não são deveres que possam ser exigidos pelos cônjuges a terceiros e, por isso, não são deveres que possam ser oponíveis pelos cônjuges

27 Cf. LeITE DE CAMpos, Lições de Direito da Família e das Sucessões² (1997), 144; Pereira Coelho/G. De OliVeira, Curso de Direito da Família I ${ }^{4}$ (2008), 158; diferentemente, ANTunes VARela, Direito da Família $I^{5}$ (1999), 369 s.; C. A. Dias, ScI 49 (2000), 353; C. A. DIAS, ScI 50 (2001), 203 ss. 
a terceiros. Isto é certamente indiscutível quanto, por exemplo, aos deveres de respeito, coabitação ou cooperação, mas também vale para o dever de fidelidade: o cônjuge tem direito à fidelidade do outro cônjuge, mas não tem direito à cooperação de um terceiro na observância do dever de fidelidade do seu cônjuge.

b) O cumprimento dos direitos pessoais não é, em regra, suscetível de ser exigido judicialmente e, menos ainda, suscetível de ser executado. A lei exclui expressamente a execução específica da promessa de casamento (cf. art. $1591 .^{\circ}$ ) e a exigibilidade judicial da compensação devida ao menor pelo seu trabalho (cf. art. $1895 .^{\circ}$, n. $^{\circ}$ 2), mas a regra não pode deixar de ser a inexigibilidade judicial dos direitos de caráter pessoal. A ordem jurídica sanciona a violação dos correspondentes deveres - permitindo, por exemplo, a dissolução do casamento por divórcio (cf. art. 1779. ${ }^{\circ}$, n. ${ }^{\circ}$ 1) ou a inibição das responsabilidades parentais (cf. art. 1915. ${ }^{\circ}$, n. $^{\circ} 1$ ) -, mas, atendendo ao caráter estritamente pessoal desses direitos, não permite a imposição do seu cumprimento através dos tribunais.

Os direitos familiares pessoais devem ser respeitados pelos membros da família, não havendo qualquer motivo para entender que, quanto a eles, vigora uma regra de "fragilidade da garantia" que deixa sem sanção a sua violação ${ }^{28}$. O que sucede é que alguns direitos familiares não contêm o poder de exigir o seu cumprimento (pense-se, por exemplo, no direito do cônjuge à fidelidade do outro cônjuge (cf. art. $1672 .^{\circ}$ ) ou no direito de respeito entre pais e filhos (cf. art. $18744^{\circ}$. n. ${ }^{\circ}$ )), mas isso não significa que a violação desses direitos não seja sancionada (a violação do dever de fidelidade atribui ao cônjuge ofendido o direito a uma indemnização (cf. art. 483..$^{\circ}$

28 No mesmo sentido, HÖSTER, ScI 44 (1995), 113 ss.; C. A. DIAS, ScI 49 (2000), 351 ss.; SIlva CERDEIRA, Da Responsabilidade Civil dos Cônjuges Entre Si (2000), 80 ss.; Pereira Coelho/G. Oliveira, Curso de Direito da Família I ${ }^{4}, 155$ ss.; DUARTE PINHEIRO, O Direito da Família Contemporâneo ${ }^{4}$ (2013), 95 ss.; cf. também BIANCHINI, Dir. fam. 39 (2010), 963 ss.; diferentemente LEITE DE CAMPOS, Lições de Direito da Família e das Sucessões², 141. 
n..$^{\circ} 1$, e $1792 .^{\circ}$, n. ${ }^{\circ}$ 1) e a violação do dever de respeito dos progenitores em relação ao filho pode conduzir à inibição do exercício das responsabilidades parentais (cf. art. 1915. ${ }^{\circ}$, n. $^{\circ} 1$ )). Portanto, a inexigibilidade do cumprimento do direito não significa qualquer enfraquecimento daquele direito, porque, mesmo quando a sua violação não constitui um dever de indemnização, esse incumprimento acaba sempre por ser sancionado.

Nesta mesma perspetiva, nada obsta a que, sempre que se trate de uma prestação de facto infungível, possa ser imposta ao membro da família uma sanção pecuniária compulsória por cada dia de atraso no cumprimento ou por cada infração (cf. art. 829. ${ }^{\circ}-\mathrm{A}, \mathrm{n}^{\circ}{ }^{\circ} 1$ ). Trata-se de uma forma de compelir o membro infrator a cumprir o que deve (impondo, por exemplo, ao progenitor que deve entregar o menor ao outro progenitor para que este possa exercer a guarda partilhada uma sanção pecuniária compulsória por cada dia de atraso nessa entrega).

\subsection{Direitos patrimoniais}

Os direitos familiares de caráter patrimonial não possuem o caráter pessoal dos direitos pessoais, pelo que o seu cumprimento pode ser exigido judicialmente. É o caso, por exemplo, do direito a alimentos (cf. art. $933 .^{\circ}$ a $937 .^{\circ} \mathrm{CPC}$ ).

Também quanto aos direitos de caráter patrimonial não há razões para lhes impor qualquer "fragilidade da garantia". Importa referir, no entanto, que, quanto a alguns direitos de caráter patrimonial, a responsabilidade do membro da família é atenuada e que, quanto a alguns outros, a sua violação nem sequer pode preencher os requisitos da responsabilidade civil. Por exemplo: (i) o cônjuge que administra bens do outro só responde pelos atos intencionalmente praticados em prejuízo do casal ou do outro cônjuge (cf. art. 1681. , n. ${ }^{\circ}$ 1), o que exclui a responsabilidade pelos atos meramente negligentes; (ii) se um dos cônjuges, sem consentimento do outro, doar 
um bem comum, a consequência é apenas a de que o valor do bem é levado em conta na sua meação (art. 1982. ${ }^{\circ}$, n. $^{\circ}$ 4), isto é, é integrado nessa meação no momento da partilha (cf. art. $1689 .^{\circ}$, n. $^{\circ}$ 1); (iii) a administração dos bens do filho integra o conteúdo das responsabilidades parentais (cf. art. 1878..$^{\circ}$ n..$^{\circ}$ 1); a má administração destes bens origina diversas consequências (cf. art. $1915 .^{\circ}$, n. ${ }^{\circ} 1$, e $1920 .^{\circ}$ ), mas nenhuma delas comporta a responsabilidade civil dos progenitores encarregados do exercício das responsabilidades parentais.

\subsection{Aspetos comuns}

O caráter estritamente pessoal dos direitos familiares implica que, em regra, eles não podem ser cedidos ou transmitidos (inter vivos ou mortis causa) (cf., por exemplo, art. $1785 .^{\circ}$, n. $^{\circ}$ 3) e não podem ser renunciados (cf. art. $1882 .^{\circ}$ e $2008 .^{\circ},{ }^{\circ}{ }^{\circ}$ ), o que é um corolário da estreita ligação daqueles direitos com os respetivos estados pessoais, também eles naturalmente intransmissíveis e irrenunciáveis. Como bem se compreende, a qualidade de cônjuge, de pai ou mãe, ou de filho não pode ser nem cedida, nem transmitida, nem renunciada. Aquela mesma característica dos direitos familiares implica que eles só podem ser exercidos pelos próprios membros, não admitindo situações de representação. Existe, no entanto, uma exceção quanto ao casamento por procuração (cf. art. 1620..$^{\circ}$ e outra quanto à perfilhação por intermédio de procurador (cf. art. 1849. ${ }^{\circ}$ ). 